\section{Estudo \\ CoDebate}

em Testão

Plamejamento
Revista Estudo \& Debate, Lajeado, v. 25, n. 2, 2018. ISSN 1983-036X

DOI: http://dx.doi.org/10.22410/issn.1983-036X.v25i2a2018.1855

\title{
EXECUÇÃO ORÇAMENTÁRIA DA SUBFUNÇÃO TURISMO: RANKING DE DESEMPENHO DOS ESTADOS E DO DISTRITO FEDERAL (2011-2015)
}

\author{
Maurício Corrêa da Silva ${ }^{1}$, Fábia Jaiany Viana de Souza², Adilson de Lima Tavares ${ }^{3}$, \\ José Dionísio Gomes da Silva ${ }^{4}$
}

\begin{abstract}
Resumo: O objetivo desta investigação é avaliar a execução orçamentária da despesa da subfunção turismo dos Estados Brasileiros e do Distrito Federal, no período de 2011 a 2015, utilizando a técnica da Análise de Componentes Principais (ACP), a fim de elaborar um índice e estabelecer um ranking de desempenho. Foi utilizado o método de pesquisa empírico-analítico com o suporte das Teorias dos Stakeholders e Agência e como critério de avaliação: a eficiência alocativa. Os resultados apontaram no ranking de desempenho dos Estados e do Distrito Federal na execução orçamentária da subfunção turismo, no período de 2011 a 2015, com a elaboração do Índice de Desempenho da Subfunção Turismo dos Estados e do Distrito Federal (IDST), que o estado do Ceará (CE), seguido de Pernambuco (PE) e Santa Catarina (SC) obtiveram as primeiras posições (mais eficientes). Nas últimas posiçóes ficaram os Estados de Rondônia - RO com a 25a posição, Rio Grande do Sul - RS, na 26a e na última posiçáo (27a), Alagoas - AL (menos eficiente).
\end{abstract}

Palavras-chave: Subfunção Turismo. Desempenho. Métrica Quantitativa.

1 Doutor em Ciências Contábeis (UnB/UFPB/UFRN - 2014/2016). Mestre em Ciências Contábeis (UnB/ UFPB/UFRN/UFPE - 2004/2005). Professor Adjunto do Departamento de Ciências Contábeis da Universidade Federal do Rio Grande do Norte (UFRN). Professor do Mestrado em Ciências Contábeis da UFRN.

2 Doutoranda em Ciências Contábeis (UFPB). Servidora do Instituto Federal de Educação, Ciência e Tecnologia do Rio Grande do Norte (IFRN). Mestra em Ciências Contábeis (UnB/UFRN/UFPB).

3 Doutor em Ciências Contábeis (UnB/UFPB/UFRN). Mestre em Ciências Contábeis (UnB/UFPB/UFRN/ UFPE - 2004/2006). Professor Adjunto do Departamento de Ciências Contábeis da UFRN. Professor do Mestrado em Ciências Contábeis da UFRN.

4 Doutor em Controladoria e Contabilidade (FEA-USP - 1995/2000). Mestre em Administração (UFRN). Professor Titular do Departamento de Ciências Contábeis da UFRN e do Mestrado em Ciências Contábeis da UFRN. 


\title{
BUDGETARY EXECUTION OF THE SUBFUNCTION TOURISM: RANKING OF PERFORMANCE OF THE STATES AND OF THE FEDERAL DISTRICT (2011-2015)
}

\begin{abstract}
The main goal of this investigation is to evaluate the budgetary execution of the expenditure of the tourism subfunction of the Brazilian States and the Federal District, in the period from 2011 to 2015, using the technique of Principal Component Analysis (PCA), in order to developing an index and establishing a performance ranking. It was used the empirical-analytical research method, with the support of the Stakeholder and Agency Theories, and the allocative efficiency was used as assessment criterion. The results indicated in the ranking of performance of the States and of the Federal District in the budgetary execution of the subfunction tourism, in the period from 2011 to 2015, with the development of the Index of Performance of the Subfunction Tourism of the States and of the Federal District (IDST), that the State of Ceará (CE), followed by Pernambuco (PE) and Santa Catarina (SC) obtained the first positions (more efficient). In the last positions were the States of Rondônia - RO in the 25th position, Rio Grande do Sul - RS, in the 26th position, and in the last position (27th) was the State of Alagoas - AL (less efficient).
\end{abstract}

Keywords: Subfunction Tourism. Performance. Quantitative Metrics.

\section{INTRODUÇÁO}

As funções de governo (educação, saúde, saneamento, comércio e serviços etc.) representam o maior nível de agregação das diversas áreas de despesa que competem ao setor público. As subfunçóes (ensino fundamental, assistência hospitalar e ambulatorial, saneamento básico urbano, turismo etc.) representam uma partição da função, visando agregar determinado subconjunto de despesa do setor público (BRASIL, 1999).

A função comércio e serviços (açôes desenvolvidas no sentido de planejar e promover a expansão do comércio interno e externo) agrega as subfunçóes: promoção comercial; comercialização; comércio exterior; serviços financeiros e turismo). A subfunção turismo compreende as açóes desenvolvidas no sentido de divulgar os atrativos turísticos, planejar e fortalecer o desenvolvimento do turismo interno no país ou na unidade da federação, e da captação de turistas estrangeiros (BRASIL, 1999).

A execução orçamentária da despesa por funçóes de governo está prevista na Lei no 4.320, de 17 de março de 1964 (BRASIL, 1964) e os conceitos de função, subfunção, programa, projeto, atividade, operaçóes especiais constam na Portaria no 42, de 14 de abril de 1999, do Ministério do Planejamento, Orçamento e Gestão - MPOG (BRASIL, 1999). A União, os Estados e o Distrito Federal adotaram a evidenciação das funções nesses procedimentos, desde o exercício financeiro de 2000 e os Municípios, a partir do ano de 2002.

As entidades públicas (União, Estados, Distrito Federal, Municípios) devem avaliar os seus programas para certificarem que os seus resultados sejam atingidos. As avaliaçóes representam uma das fases das análises das políticas públicas. O desempenho do gestor público de forma eficiente é uma exigência constitucional (SILVA, 2016). Para Secchi (2013), os indicadores são utilizados para operacionalizar os critérios de avaliação das políticas públicas e funcionam como artifícios (proxies) que podem ser criados para medir input, output e outcome. 
A utilização de indicadores e/ou índices de desempenho para aferir os resultados dos administradores públicos está relacionada ao conceito de gerenciamento voltado para resultados e são usados para medir economicidade, eficácia, eficiência e efetividade (BRASIL, 2010).

As informações sobre desempenho são essencialmente comparativas (BRASIL, 2010) e a palavra desempenho é um termo sujeito a inúmeras variaçóes semânticas e conceituais (BRASIL, 2009). A análise de desempenho pode ser efetuada sob a ótica de uma organização que deseja melhorar seu desempenho, comparativamente a outras unidades (LINS; CALÔBA, 2006).

Diante do acima exposto, surge a seguinte questão de pesquisa: Qual o ranking de desempenho dos Estados Brasileiros e do Distrito Federal na execução orçamentária da despesa da subfunçáo turismo, no período de 2011 a 2015? Assim, o objetivo desta investigação é avaliar a execução orçamentária da despesa da subfunção turismo dos Estados Brasileiros e do Distrito Federal, no período de 2011 a 2015, utilizando a técnica da Análise de Componentes Principais (ACP), a fim de elaborar um índice e estabelecer um ranking de desempenho.

A investigação justifica-se pela relevância que a estratégia da pesquisa de avaliação de resultados tem para os cidadãos e para os gestores públicos. Os cidadãos poderão ser motivados a buscarem informaçóes sobre o desempenho administrativo dos seus gestores. Neste sentido, Diniz, Macedo e Corrar (2012) argumentam que a população brasileira não tem essa cultura e que a informação que está mais em evidência diz respeito às denúncias e à apuração de condutas relacionadas com a corrupção. Os gestores públicos poderão incluir em suas rotinas a utilização de indicadores. Zucatto et al. (2009) esclarecem que um indicador pode ser definido como um parâmetro que medirá a diferença entre a situação desejada e a situação atual, ou seja, ele indicará um problema.

Os eleitores deveriam estar bem informados a respeito de como as receitas e despesas de seus governos estaduais e/ou municipais se comparam com os de outras regióes no que diz respeito a sua capacidade financeira em relação à oferta de serviços públicos (ROSENBLATT; SHIDLO, 1996).

Os estudos na área do turismo abordam diversas vertentes: potenciais de serviços turísticos (ALMEIDA, 2003); dispêndios públicos do Estado de Pernambuco com turismo (MEIRELLES, 2009); cadeia produtiva (CORREAA; MARIANI; VELOSO, 2011); impactos socioeconômicos (BARBOSA; MARTELOTTE; ZOUAIN, 2006; BASTOS, 2012); viabilidade da implementação do plano de turismo (ARAÚJO; POSENATTO, 2012), envolvimento dos stakeholders nas estratégias existentes na atividade do turismo (COSTA et al., 2016), dentre outros.

Desse modo, a pesquisa contribui no esclarecimento e auxílio para a sociedade em encontrar suporte e orientaçóes para o controle social. O tema é importante para o desenvolvimento do turismo nas regiōes analisadas, haja vista que os cidadãos esperam eficiência (princípio constitucional) na aplicação dos recursos por eles disponibilizados. Há também uma contribuição para a literatura de avaliação de recursos públicos na subfunção 
turismo ao apresentar a métrica quantitativa para elaborar o índice de desempenho dos recursos aplicados pelos Estados e do Distrito Federal, em cinco exercícios financeiros.

A pesquisa está amparada pelas Teorias dos Stakeholders e Agência (casos de aplicação), além de revisitar questóes sobre a avaliação de desempenho no setor público e, para atingir o objetivo proposto, este artigo está dividido em cinco seçóes. Após esta introdução, a seção dois traz a revisão da literatura. A seção seguinte os procedimentos metodológicos. A quarta seção mostra os resultados da pesquisa e discussóes. A quinta seção trata das considerações finais.

\section{REVISÃO DA LITERATURA}

\subsection{Avaliaçáo de desempenho no setor público}

A avaliação de desempenho para Helden, Johnsen e Vakkuri (2008) é entendida como um instrumento para indicar eficiência, eficácia e equidade no contexto do setor público. É utilizada principalmente para aumentar a racionalidade na tomada de decisão nas organizaçóes, além de auxiliar na prestação de contas, no planejamento e controle. Costa e Castanhar (2003) asseveram que independentemente da conjuntura da crise, o Estado é obrigado a proceder à avaliação regular de seus programas e atividades.

Um programa público pode ser avaliado em relação ao desempenho de efetividade das metas alcançadas; efetividade social e institucional; indicadores de eficácia (sistema gerencial e decisório) e indicadores de eficiência do custo/benefício (DRAIBE, 2001). A execução orçamentária de um programa é monitorada durante a sua implementação e avaliada ex ante e ex post (RAMOS; SCHABBACH, 2012).

Os indicadores sociais são medidas usadas para traduzir um conceito abstrato e informar algo sobre determinado aspecto da realidade para fins de pesquisa. Os índices de desempenhos são utilizados com o mesmo sentido (SILVA, 2016).

Figueiredo Filho et al. (2013) esclarecem que os indicadores sociais têm um papel essencial para a implementação e avaliação de desempenho das políticas públicas. Neste contexto, avaliar a execução orçamentária dos Estados e do Distrito Federal na subfunção turismo é importante para contribuir com o desenvolvimento do país, haja vista que não foram encontrados artigos científicos que tratam desses indicadores.

Silva e Silva (2017) argumentam que a execução orçamentária da despesa por funções de governo representa os resultados decorrentes das decisóes dos gestores de diferentes ideologias partidárias (mudanças de governo), do cumprimento dos limites obrigatórios e constitucionais (restriçóes ao poder discricionário no orçamento) dos gastos, das mudanças de orientação dos instrumentos de planejamento do setor público (Plano Plurianual; Lei de Diretrizes Orçamentárias e Lei Orçamentária Anual). Enfim, representam a realidade das aplicaçóes dos recursos em prol da sociedade.

Jannuzzi (2002) esclarece que os indicadores sociais se prestam a subsidiar as atividades de planejamento público e formulação de políticas sociais nas diferentes esferas de governo. Possibilitam o monitoramento, por parte do poder público e da sociedade 
civil, das condiçôes de vida e bem-estar da população e permitem o aprofundamento da investigaçáo acadêmica sobre a mudança social e os determinantes dos diferentes fenômenos sociais.

Para Zucatto et al. (2009), os indicadores são importantes ferramentas gerenciais para a administração pública e instrumento fundamental para a fiscalização da gestão pública por parte dos movimentos populares, haja vista que aumentam a transparência na gestão e facilitam o diálogo entre os mais diversos grupos sociais organizados.

A avaliação de desempenho com a utilização de índices e/ou indicadores sociais, elaborados com métrica quantitativa, serve de instrumento para indicar a eficiência no setor público, pois utiliza critérios estatísticos para simplificar e tornar as informaçôes mais fáceis de serem compreendidas.

$\mathrm{Na}$ auditoria operacional, os indicadores de desempenho são usados para medir economicidade, eficácia, eficiência e efetividade (BRASIL, 2010). Para o Tribunal de Contas da União (TCU), nas avaliaçóes de desempenho devem ser feitas comparaçóes com metas ou padrões preestabelecidos, ou realizada uma comparação com os resultados atingidos em períodos anteriores, obtendo-se assim uma série histórica para análise de desempenho (BRASIL, 2000).

A palavra desempenho, segundo o Ministério do Planejamento, Orçamento e Gestão -MPOG (BRASIL, 2009), é um termo sujeito a inúmeras variações semânticas e conceituais e segundo uma abordagem abrangente, o desempenho pode ser compreendido como esforços empreendidos na direçâo de resultados a serem alcançados.

O desempenho é um conceito multifacetado que vem sendo explorado por uma variedade de campos do conhecimento como Contabilidade, Estratégia, Recursos Humanos, Produção e Gestão de Operaçôes, Marketing, Comportamento Organizacional e Gestão Estratégica (FRANCO-SANTOS; LUCIANETTI; BOURNE, 2012).

Depreende-se com base nas afirmaçōes do TCU (BRASIL, 2000), do MPOG (BRASIL, 2009) e de Franco-Santos, Lucianetti e Bourne (2012) que os termos "avaliação de desempenho", "indicadores de desempenho" e "medição de desempenho" podem ser considerados como sinônimos, haja vista a existência de variaçôes semânticas e conceituais multifacetadas do termo desempenho. Neste sentido, a utilização de uma métrica quantitativa para elaborar índice de desempenho que utiliza todas as variáveis escolhidas podem resultar em inferências para as principais partes interessadas na área do turismo, delimitado nos gastos públicos (execuçâo orçamentária da despesa) estaduais e distrital, nesta investigação.

\subsection{Teoria dos Stakeholders}

O principal marco da Teoria dos Stakeholders tem sido, normalmente, sido atribuído à obra de Robert Edward Freeman de 1984, quando publicou seu livro de referência e desde entáo vários ensaios foram publicados com o objetivo de compor o mosaico desta teoria (GOMES, 2006). Para McWilliams e Siegel (2001), o trabalho de Freeman é tido como seminal na fundamentação da Teoria dos Stakeholders. 
Donaldson e Preston (1995) argumentam que a Teoria dos Stakeholders tem avançado e justificada na literatura de gestão com base em sua precisão descritiva, poder instrumental e validade normativa. Contudo, para Mitchell, Agle e Wood (1997), essa teoria não atingiu o status teórico completo e assim, fizeram contribuiçóes relacionadas com os atributos: poder, legitimidade e urgência.

A análise da Teoria dos Stakeholders, para Freeman et al. (2010), no processo de políticas públicas é útil para mapear os grupos constituintes, a estrutura de poder, as redes de políticas e a comunidade. Neste sentido, pode ser usada para identificar o potencial de cada parte interessada em controlar o grupo, formar coalizaçáo, identificar o poder relativo etc.

Cabral, Fernandes e Ribeiro (2016) esclarecem que a aplicação da Teoria de Stakeholders no âmbito do setor público fornece uma visão em perspectiva acerca dos padróes de atuação de grupos distintos de stakeholders em arranjos organizacionais.

De acordo com Harrison, Rouse e De Villiers (2012), na perspectiva da Teoria dos Stakeholders, a prestação de contas e a medição de desempenho pode e deve ser utilizada no setor público para identificar as partes interessadas. A Teoria dos Stakeholders pode ser ligada a temas em contabilidade e accountability (CONNOLLY; HYNDMAN, 2013). Para Boaventura (2012), as organizaçóes, invariavelmente, contraem obrigaçóes com múltiplos stakeholders cujas demandas não podem ser atendidas na sua totalidade.

Observa-se que as pesquisas de Mitchell, Agle e Wood (1997) e de Boaventura (2012) objetivaram em parte fazerem contribuiçóes para a Teoria dos Stakeholders, o que não é o caso da presente investigação. A teoria é utilizada com base, ou seja, caso prático de aplicação.

Harrison, Freeman e Abreu (2015) afirmam que a Teoria dos Stakeholders é uma perspectiva útil para abordar questóes das organizaçóes, pois oferece oportunidade de reinterpretar uma variedade de conceitos, modelos e fenômenos através de disciplinas diferentes, como economia, administração pública, finanças, filosofia, marketing, direito e gestấo.

Segundo Vieira, Costa e Boaventura (2011), a definição clássica de stakeholders, corresponde a qualquer grupo ou pessoa cujos interesses podem afetar ou ser afetados pelas realizações dos objetivos de uma organização. A Teoria dos Stakeholders é usada para identificar quem são os Stakeholders, quais são as suas características, quais são as suas motivaçōes e os recursos disponíveis.

Segundo Sarturi, Seravalli e Boaventura (2015), o atendimento dos interesses e das demandas dos stakeholders leva em conta aspectos de distribuição de valor pelas empresas, tais como: salários; produtos de qualidade; segurança no trabalho etc. Pode-se assim, estender o entendimento para a gestão pública para analisar os retornos para os cidadãos.

Para Costa et al. (2016), a visão dos stakeholders permite compreender a dinâmica local do turismo, suas especificidades, sobretudo na perspectiva dos próprios atores que, por meio de suas percepçóes, e de documentos efetivados, configuram o desenho das complexas inter-relações necessárias para dinamizar, econômica e socialmente um setor, além da sua exigência ambiental. 
A Teoria dos Stakeholders no contexto da pesquisa de avaliação de resultados da administração pública fornece subsídios para identificar e discutir o papel das partes interessadas (stakeholders) na gestâo da coisa pública, pois utiliza conceitos de sociologia, comportamento organizacional e administração de conflitos. Ou seja, é um caso prático de aplicação da teoria e não de contribuição teórica para compor o seu mosaico.

\subsection{Teoria da Agência}

A Teoria da Agência foi formalizada no artigo seminal de Jensen e Meckling (1976) para explicar o relacionamento entre agentes nas trocas econômicas, em que um ator (o principal) tem poder sobre o comportamento de um outro ator (o agente) em seu favor, e o bem-estar do principal sofre influência das decisóes do agente.

Segundo Pinto et al. (2014), a Teoria da Agência se ajusta ao controle social, sendo esse último uma ferramenta capaz de preencher as lacunas apontadas na relaçáo entre sociedade (principal) e gestores públicos (agente). A distinção entre agente e principal na gestão pública é um pressuposto do processo democrático, assim, por mais que no momento da escolha do agente (pelo voto) as propostas pareçam revelar alinhamento de interesses, na gestáo propriamente dita a falta de transparência e as dificuldades de controle, criam condiçóes para o surgimento de comportamentos oportunistas.

O problema da agência decorre dos interesses divergentes entre o principal e o agente e da existência da assimetria da informação, em razáo do problema de surgir no momento em que as informaçôes disponíveis são desiguais entre os participantes (LERUTH; PAUL, 2006; ARROW, 1984).

Suzart (2012) afirma, com base na Teoria da Agência, que há evidências de que os gestores públicos, ao invés de atenderem aos anseios sociais, podem buscar saciar interesses pessoais. O aumento do número de notícias sobre desvios e má gestão de recursos públicos corroboram com a assertiva.

Marôcco (2009) esclarece que o modelo da Teoria da Agência encontra, no contexto da administraçáo pública, subsídios para evidenciar o problema de agência ao destacar a questão da assimetria de informação presente no relacionamento entre o Estado (principal) e o agente burocrático.

Araújo e Sanchez (2005) esclarecem que segundo a Teoria da Agência, o problema na relaçáo governo e a sociedade reside na assimetria de informação, ou seja, no fato de duas partes que se relacionam não deterem o mesmo conhecimento, colocando uma das partes quem delega responsabilidades - em desvantagens no relacionamento com a outra. MatiasPereira (2005) argumenta que numa organização quem delega responsabilidade a outro indivíduo é denominado de agente, o qual age de acordo com os seus objetivos privados. O problema reside no fato de que, na administração em geral e na pública em particular, torna-se difícil a fiscalização do comportamento do agente.

A Teoria da Agência aplicada no setor público nas pesquisas avaliativas serve para avaliar o papel dos cidadãos (principais) que delegam competência sobre a gestão pública para os gestores (agentes), além de poder diminuir a assimetria da informação entre os cidadáos que desconhecem a gestáo e os gestores que conhecem ao evidenciar os seus 
resultados. De modo similar com a Teoria dos Stakeholders, trata-se de um caso prático de aplicação da Teoria da Agência e não de contribuir para o seu mosaico.

Observa-se que o uso dos índices de desempenho desta investigação, aliado com as contribuiçóes das análises de resultados, ou seja, de casos de aplicação da Teoria dos Stakeholders (identificação e o papel dos principais stakeholders da gestão pública do turismo) e da Agência (assimetria da informação) tem a finalidade de preencher uma lacuna na literatura no campo da pesquisa pública. Assim, ao responder o problema investigado, os resultados poderão ser úteis para os gestores avaliarem suas gestóes de forma comparativa e os cidadãos entenderem como seus recursos foram utilizados.

\section{PROCEDIMENTOS METODOLÓGICOS}

\subsection{Caracterizaçóes da pesquisa e do método}

Esta investigação utiliza a estratégia da pesquisa de avaliação de resultados. Para Martins e Theóphilo (2009), essa é uma estratégia empírica aplicada para avaliar programas, projetos, políticas etc. O método de pesquisa utilizado é o empírico-analítico (arquivo/ empirista - banco de dados) que corresponde à utilização de técnica de coleta, tratamento e análise de dados com métricas quantitativas. Matias-Pereira (2012) esclarece que nesse método, o processo de validação da prova científica é feito por meio de testes dos instrumentos, graus de significância e sistematização das definiçóes operacionais.

A métrica quantitativa é utilizada para calcular o índice de desempenho e está fundamentada na Teoria da Medição (ARIAS, 2010; COHEN; FRANCO, 2012; STEVENSON, 1981; BASTOS; KELLER, 2004; MARTINS, 2005).

Para Arias (2010), a Teoria da Representação da Medição ou simplesmente Teoria da Medição, a medição, no sentido mais amplo, é a atribuiçấo de números a objetos ou eventos, de acordo com as regras. $\mathrm{O}$ autor esclarece ainda, que a estatística é uma ciência útil para a pesquisa empírica, seja em psicologia ou qualquer outra ciência. É geralmente conhecida como a ciência dos grandes números, porque suas leis e princípios atingem o seu prazo de validade máximo em grandes conjuntos de casos ou eventos.

De acordo com Cohen e Franco (2012), pela Teoria da Medição, os números são símbolos com dois significados: o quantitativo habitual, que implica que com eles podem ser realizadas operaçóes algébricas, e o qualitativo, que pode significar uma denominação arbitrária ou estabelecer uma ordem.

Martins (2005) esclarece que a estatística não cria leis ou teorias, seu grande valor está em fornecer subsídios para que o pesquisador utilize as informaçóes relevantes, visando à construção ou verificação de teorias. Stevenson (1981) argumenta que a estatística compreende a organização, o resumo e, em geral, a simplificação de informaçóes que podem ser muito complexas. A finalidade é tornar as coisas mais fáceis de entender, de relatar e de discutir.

Bastos e Keller (2004) argumentam que a corrente metodológica do empirismo (pesquisa quantitativa) coloca a mensuração quantitativa como critério do que seria ou não 
científico, do que seria ou não verdadeiro. $\mathrm{O}$ empirismo busca reproduzir as condições do fenômeno em laboratório, com a pretensão de reconstruir o ambiente propício capaz de superar subjetivismos, incursóes de juízos de valor e influências ideológicas.

Convém ressalvar que a utilização da Teoria da Medição nos procedimentos metodológicos tem a finalidade de ratificar a importância da utilização de métricas quantitativas na elaboração de instrumentos de avaliação de desempenho nas pesquisas de resultados de gestôes públicas.

\subsection{Base de dados, variáveis e critério de avaliaçáo}

A população (universo), desta investigação, é constituída de todos os Estados Brasileiros e o Distrito Federal (a relação consta na Tabela 1). Não há amostra (foram obtidos dados dos 26 Estados e do Distrito Federal).

Para compor o índice de desempenho, foram escolhidas como variáveis os gastos per capita da subfunçáo turismo, no período de 2011 a 2015 (aspecto temporal). O aspecto temporal leva em conta a disponibilidade de dados por ocasiáo da elaboraçáo desta investigação e a necessidade de delimitar os dados em uma pesquisa (critério do investigador). Aliás, as execuçóes orçamentárias de 2016 e 2017 não estavam disponibilizadas e por falta de dados do ano de 2010, não pode realizar a avaliação de uma série histórica maior.

A comparação de gastos entre instituiçôes está respaldada nas afirmações de Brown (1993) e Maher e Nollenberger (2009): podem ser feitas avaliações de desempenho entre municípios e estados, considerando a quantidade de habitantes.

A Tabela 1 apresenta os valores utilizados (aplicados) pelos Estados e pelo Distrito Federal na subfunção turismo, no período de 2011 a 2015.

Tabela 1 - Variáveis do estudo: subfunção turismo - per capita, no período de 2011 a 2015

\begin{tabular}{llccccc}
\hline & Estados e o Distrito Federal & $\mathbf{2 0 1 1}$ & $\mathbf{2 0 1 2}$ & $\mathbf{2 0 1 3}$ & $\mathbf{2 0 1 4}$ & $\mathbf{2 0 1 5}$ \\
\hline 1 & Acre (AC) & 2,2727 & 8,9983 & 9,0932 & 6,7561 & 3,7012 \\
2 & Alagoas (AL) & 0,4709 & 0,3366 & 0,1384 & 0,3522 & 0,0836 \\
3 & Amapá (AP) & 1,3453 & 3,5313 & 3,9343 & 3,6314 & 0,0766 \\
4 & Amazonas (AM) & 2,0518 & 4,3514 & 6,3315 & 6,3456 & 2,5776 \\
5 & Bahia (BA) & 3,3349 & 3,5582 & 3,5943 & 3,8711 & 1,3326 \\
6 & Ceará (CE) & 28,4680 & 19,6937 & 8,9133 & 9,5749 & 5,2161 \\
7 & Distrito Federal (DF) & 1,5637 & 1,5361 & 0,8140 & 1,8646 & 0,1444 \\
8 & Espírito Santo (ES) & 1,0070 & 1,5330 & 0,6717 & 0,8493 & 0,3357 \\
9 & Goiás (GO) & 2,3372 & 4,1954 & 8,2433 & 5,8197 & 4,3676 \\
10 & Maranhão (MA) & 1,0756 & 1,6971 & 0,2470 & 0,2045 & 0,2243 \\
11 & Mato Grosso (MT) & 5,6403 & 2,2003 & 8,2151 & 10,7479 & 3,9690 \\
12 & Mato Grosso do Sul (MS) & 2,4866 & 2,7637 & 2,3353 & 2,4585 & 1,1553 \\
13 & Minas Gerais (MG) & 0,1922 & 0,6195 & 0,5126 & 0,5780 & 0,0977
\end{tabular}




\begin{tabular}{|c|c|c|c|c|c|c|}
\hline & Estados e o Distrito Federal & 2011 & 2012 & 2013 & 2014 & 2015 \\
\hline 14 & Pará (PA) & 0,3807 & 0,7867 & 1,8825 & 2,3841 & 0,5708 \\
\hline 15 & Paraíba (PB) & 0,3267 & 0,5129 & 0,4378 & 1,7177 & 0,3215 \\
\hline 16 & Paraná (PR) & 0,8561 & 0,9953 & 1,1607 & 0,5348 & 0,4903 \\
\hline 17 & Pernambuco (PE) & 12,3912 & 10,9238 & 10,8197 & 12,4104 & 5,6491 \\
\hline 18 & Piauí (PI) & 1,3989 & 1,3934 & 2,1008 & 1,0801 & 1,9356 \\
\hline 19 & Rio de Janeiro (RJ) & 0,7505 & 0,7211 & 0,2401 & 0,6231 & 0,3579 \\
\hline 20 & Rio Grande do Norte (RN) & 1,7193 & 1,1080 & 0,5666 & 0,3551 & 0,4653 \\
\hline 21 & Rio Grande do Sul (RS) & 0,7632 & 0,3399 & 0,3736 & 0,4670 & 0,0475 \\
\hline 22 & Rondônia (RO) & 0,2981 & 1,4514 & 0,3570 & 0,0060 & 0,0760 \\
\hline 23 & Roraima (RR) & 0,4073 & 1,2254 & 0,8804 & 0,1097 & 0,0675 \\
\hline 24 & Santa Catarina (SC) & 10,3065 & 11,8018 & 8,7678 & 6,9209 & 5,8016 \\
\hline 25 & São Paulo (SP) & 0,1432 & 6,9506 & 6,5207 & 6,3575 & 3,9047 \\
\hline 26 & Sergipe (SE) & 2,3063 & 1,7009 & 0,9825 & 1,4160 & 2,1589 \\
\hline 27 & Tocantins (TO) & 2,0948 & 3,1097 & 1,0123 & 1,8313 & 0,8533 \\
\hline
\end{tabular}

Observação: valores em R\$ 1,00.

Fonte: dados da pesquisa.

Observa-se na Tabela 1, que em termos per capita no período avaliado, os Estados do Ceará (CE), seguido por Pernambuco (PE) e Santa Catarina (SC) foram os que mais aplicaram recursos na subfunção turismo.

Os gastos per capita da subfunção turismo (variáveis escolhidas) relativizam as diferenças existentes entre os Estados e o Distrito Federal para calcular o desempenho em relação aos recursos disponibilizados nos exercícios financeiros de 2011 a 2015. Neste sentido, a delimitação é necessária, haja vista que avaliar/analisar todo o universo da política que envolve turismo (transporte; gastronomia; infraestrutura hoteleira; aeroportos etc.) não é possível. Segundo Silva, Silva e Silva (2016), não é possível realizar avaliaçóes do todo (universo). As avaliações são realizadas com aproximaçōes (proxies) do universo.

Os dados sobre a execução orçamentária da subfunção turismo foram extraídos do sítio eletrônico da Secretaria do Tesouro Nacional - STN (BRASIL, 2017).

Para avaliar o desempenho da execução orçamentária, dos programas do governo, os resultados das açóes de governo e as funçóes de governo de forma agregada ou individual são necessários estabelecer os critérios (CAIDEN; CAIDEN, 2001; COSTA; CASTANHAR, 2003; SECCHI, 2013). Nesta investigação, o critério estabelecido é o da eficiência alocativa.

Os recursos alocados por um governo traduzem o tipo e a natureza do padrão de preferências alocativas de tal governo (REZENDE, 1997). As preferências alocativas se referem à divisão dos recursos financeiros públicos como sendo o fim último da ação do governo.

A eficiência alocativa avalia a relaçáo entre os recursos gerais da sociedade e os resultados obtidos através da sua utilização em termos de obtenção de bem-estar para todos 
os indivíduos (GIRALDES, 2005). Segundo Bugarin (2001), a eficiência alocativa, trata a questão de como distribuir os recursos e a própria produção.

A eficiência alocativa mostra a capacidade de uma unidade escolher um conjunto de insumos (CATALÁN; BALLVE, 2009). A eficiência alocativa é alcançada quando os recursos são distribuídos de uma forma que maximiza o bem-estar da sociedade (NINA; FERNÁNDEZ, 2011).

Neste contexto, esta pesquisa avalia a eficiência da alocação dos recursos financeiros (inputs) para atender às comunidades de forma agregada na subfunção turismo, a partir de uma visão macro de desempenho entre os gestores públicos. $\mathrm{O}$ desempenho é apurado pelo resultado da ponderação dos coeficientes e as variâncias das variáveis definidas em relação aos escores padronizados, a partir de equaçóes lineares. $\mathrm{O}$ efeito prático da avaliação é que o melhor desempenho traduz a melhor eficiência alocativa dos recursos públicos estaduais e distrital.

Observa-se assim, que os elementos do ranking de desempenho são constituídos dos recursos que foram alocados pelos Estados e o Distrito Federal na subfunção turismo, nos anos de 2011 a 2015, os quais são denominados de escores padronizados multiplicados pelos coeficientes (autovetores) extraídos com base nos componentes principais (álgebra). Contudo, antes das variáveis (gastos per capita na subfunção turismo) serem utilizadas como escores padronizados (z-escore), através de procedimentos de álgebra linear são extraídos os autovalores (variâncias dessas variáveis) em 5 componentes principais (5 variáveis). Depois é extraído os autovetores pela razão entre os componentes principais da matriz de componentes e a raiz quadrada dos autovalores. Os autovetores é que são multiplicados pelos escores padronizados. O Quadro 1 apresenta o modelo empírico utilizado na pesquisa com base na literatura sobre a técnica da Análise de Componentes Principais (ACP).

\subsection{Mensuração quantitativa e modelo estatístico}

A técnica de análise e interpretação dos dados escolhida para avaliar o desempenho dos governos dos Estados e do Distrito Federal na execução orçamentária da subfunção turismo com a utilização de índice foi a Análise de Componentes Principais (ACP). O modelo estatístico para a utilização da técnica segue as orientações de Kaiser (1960), Mingoti e Silva (1997), Kubrusly (2001), Timm (2002), Jolliffe (2002), Osborne e Costello (2004), Mingoti (2007), Ayres (2012), Vyas e Kumaranayake (2006), Johnson e Wichern (2007), Manly (2008), Field (2009), Lattin, Carroll e Green (2011) e Ribas e Vieira (2011).

Em termos matemáticos, a partir de um conjunto inicial de $n$ variáveis correlacionadas, a Análise de Componentes Principais (ACP) cria índices ou componentes não correlacionados, sendo que cada componente é uma combinação linear ponderada das variáveis iniciais (VYAS; KUMARANAYAKE, 2006). Na construção de índices com combinaçóes lineares de variáveis é desejável que estes tenham a maior variância possível (KUBRUSLY, 2001).

O primeiro componente é um índice de desempenho global de acordo com Mingoti (2007) e Manly (2008) esclarece que em termos de ordenação, pode esperar que os primeiros componentes principais sejam suficientes para descreverem as diferenças entre os 
objetos. Para Ribas e Vieira (2011), cada componente é uma função linear. Os componentes principais são usados para descobrir e interpretar as dependências que existem entre as variáveis (TIMM, 2002).

O modelo empírico para calcular o índice de desempenho com base na literatura citada consta no Quadro 1.

Quadro 1 - Modelo empírico das equaçóes lineares para calcular o índice de desempenho com a Análise de Componentes Principais (ACP)

\begin{tabular}{|l|}
\hline$Y_{n}=A_{1} Z_{1}+A_{2} Z_{2}+\ldots+A_{n} Z_{n}$ \\
\hline$Y_{n}=$ equaçóes lineares (escores de desempenhos dos componentes principais); \\
\hline$A_{n}=$ autovetores (coeficientes das variáveis - pesos); \\
$Z_{n}=$ variáveis padronizadas $(X-\bar{X}) /$ desvio-padrão de $X$ (variáveis menos a média das variáveis \\
divididas pelo desvio-padrão das variáveis);
\end{tabular}

Fonte: elaborado pelos autores.

Manly (2008) e Ayres (2012) esclarecem que os autovalores representam o poder explicativo do componente em relação à variância das variáveis originais (observadas) e os autovetores são os coeficientes das variáveis $\mathrm{X}$ padronizadas usados para calcular escores dos componentes principais. Para Kaiser (1960), deve ser utilizado autovalores com valores acima de 1 . As variáveis não dependem de qualquer suposição de normalidade (MINGOTI; SILVA, 1997) e para podem ser contínuas e distribuídas normalmente ou não (JOLLIFFE, 2002).

As variáveis padronizadas (escore padrão ou z-escore), segundo Larson e Farber (2010), representam o número de desvios-padrão que um valor dado está a partir da média. Um $z$-escore pode ser negativo, positivo ou zero. Se for negativo, o valor está abaixo da média. Se positivo, o valor correspondente está acima da média e se for zero, o valor correspondente é igual a média. Segundo Martins (2002), o z-escore (escore padronizado), representa uma forma de demonstrar a melhor performance (desempenho) relativa. $\mathrm{O}$ z-escore são utilizados nas equaçóes lineares.

\section{RESULTADOS E DISCUSSÓES}

O Quadro 2 apresenta a equação linear utilizada para calcular o desempenho dos Estados e do Distrito Federal com base na técnica da Análise de Componentes Principais (ACP). 
Quadro 2 - Equação utilizada para o cálculo do desempenho

$\mathrm{Y}_{1}=0.4040 \mathrm{Z}_{1}+0.4518 \mathrm{Z}_{2}+0.4603 \mathrm{Z}_{3}+0.4558 \mathrm{Z}_{4}+0.4614 \mathrm{Z}_{5}$

Variáveis padronizadas (subfunção turismo per capita): $Z_{1}=$ ano de $2011 ; Z_{2}=$ ano de 2012; $Z_{3}=$ ano de $2013 ; Z_{4}=$ ano de $2014 ; Z_{5}=$ ano de 2015

Autovalor do componente $1=4.2032(84.06 \%)$

Fonte: Dados da pesquisa.

Foram extraídos cinco componentes principais com os seus respectivos autovalores $(4.2032+0.5736+0.1269+0.0785+0.0177=5$, que corresponde a variância total, ou seja, 5 variáveis observadas). Os autovetores do componente 1 (coeficientes) constam no Quadro 2 (0.4040; 0.4518; 0.4603; 0.4558; e 0.4614).

O autovalor do componente 1 possui uma variância de $84.06 \%\left(4.2032 / 5^{*} 100\right)$ - Quadro 2. Desse modo, é necessário utilizar apenas os escores desse componente para calcular o desempenho dos Estados e do Distrito Federal - variância superior a 80\% (Manly, 2008).

Para melhorar as cargas fatoriais de cada variável e assim maximizar a soma das variâncias de cargas exigidas pela matriz, foi utilizada, nesta investigação, a rotação dos eixos denominada de Varimax (simplificação das colunas da matriz fatorial - rotação ortogonal), conforme recomendaçáo feita por Field (2009).

É necessário que haja correlaçáo entre as variáveis para utilizar a Análise de Componentes Principais (ACP) e que não sejam independentes (MINGOTI, 2007; FIELD, 2009; LATTIN; CARROLL; GREEN, 2011). A matriz de correlação não pode ser identidade (FIELD, 2009). Não há consenso sobre o tamanho da amostra (OSBORNE; COSTELLO, 2004), mas quanto mais variáveis, melhor os resultados (JOHNSON; WICHERN, 2007).

A Tabela 2 apresenta os dados necessários para validar a utilização da Análise de Componentes Principais (ACP).

Tabela 2 - Validação da utilização da Análise de Componentes Principais (ACP)

\begin{tabular}{|c|c|c|c|c|c|}
\hline \multicolumn{6}{|c|}{ Matriz de Correlaçáo } \\
\hline Anos & 2011 & 2012 & 2013 & 2014 & 2015 \\
\hline 2011 & 1 & - & - & - & - \\
\hline 2012 & 0.8880 & 1 & - & - & - \\
\hline 2013 & 0.6132 & 0.7966 & 1 & - & - \\
\hline 2014 & 0.6604 & 0.7579 & 0.9534 & 1 & - \\
\hline 2015 & 0.6713 & 0.8158 & 0.9367 & 0.8930 & 1 \\
\hline p-valor & & & & & \\
\hline \multicolumn{6}{|c|}{ Teste de Esfericidade de Bartlett - Qui-quadrado aproximado } \\
\hline \multicolumn{4}{|l|}{ Calculado } & \multicolumn{2}{|c|}{182.380} \\
\hline \multicolumn{4}{|c|}{ Graus de liberdade } & \multicolumn{2}{|c|}{10} \\
\hline \multicolumn{4}{|c|}{ Significância } & \multicolumn{2}{|c|}{0.000} \\
\hline \multicolumn{4}{|c|}{ Valor crítico (tabela de distribuição) } & \multicolumn{2}{|c|}{18.3070} \\
\hline
\end{tabular}

Fonte: dados da pesquisa. 
Observa-se na Tabela 2, que a correlação é significativa no nível 0.01 (2 extremidades com o p-valor de 0.000). O Teste de Esfericidade de Bartlett apontou que as variáveis não são mutuamente independentes (matriz não é identidade), ou seja, o qui-quadrado calculado é maior o valor crítico (tabela). Os cálculos foram realizados com o software BioEstat $5.0^{\circledR}$ (AYRES et al., 2007).

Convém ressalvar que os esclarecimentos detalhados sobre a utilização da Análise de Componentes Principais (ACP), nesta investigação, visam enfatizar a elaboração de índices de desempenho com essa técnica. ACP elabora índice de desempenho sem a necessidades de utilizar outras métricas quantitativas. Os resultados das equaçóes lineares evidenciam o desempenho de cada entidade ou órgão incluído na avaliação. Desse modo, os procedimentos constituem contribuiçóes para a literatura para que outros pesquisadores utilizem tanto no setor público como no setor privado.

A Tabela 3 apresenta o ranking de desempenho dos Estados e do Distrito na execução orçamentária da subfunção turismo, no período de 2011 a 2015. Nesta investigação, o índice foi denominado de Índice de Desempenho da Subfunção Turismo dos Estados e do Distrito Federal (IDST). Os resultados evidenciam a eficiência alocativa dos recursos financeiros no atendimento dos contribuintes (principais stakeholders) na execução orçamentária da subfunção avaliada.

Tabela 3 - Ranking de desempenho dos Estados e do Distrito na execução orçamentária da subfunção turismo, no período de 2011 a 2015

\begin{tabular}{rlrrlr}
\hline $\mathbf{P}$ & Estados/Distrito Federal & IDST & $\mathbf{P}$ & Estados/Distrito Federal & IDST \\
\hline $1^{\circ}$ & Ceará (CE) & 1 & $14^{\circ}$ & Tocantins (TO) & 0.1181 \\
$2^{\circ}$ & Pernambuco (PE) & 0.8269 & $15^{\circ}$ & Pará (PA) & 0.0863 \\
$3^{\circ}$ & Santa Catarina (SC) & 0.6938 & $16^{\circ}$ & Distrito Federal (DF) & 0.0663 \\
$4^{\circ}$ & Mato Grosso (MT) & 0.5179 & $17^{\circ}$ & Espírito Santo (ES) & 0.0471 \\
$5^{\circ}$ & Acre (AC) & 0.5165 & $18^{\circ}$ & Paraná (PR) & 0.0465 \\
$6^{\circ}$ & Goiás (GO) & 0.4423 & $19^{\circ}$ & Rio Grande do Norte (RN) & 0.0418 \\
$7^{\circ}$ & São Paulo (SP) & 0.4235 & $20^{\circ}$ & Paraíba (PB) & 0.0374 \\
$8^{\circ}$ & Amazonas (AM) & 0.3603 & $21^{\circ}$ & Maranháo (MA) & 0.0279 \\
$9^{\circ}$ & Bahia (BA) & 0.2313 & $22^{\circ}$ & Rio de Janeiro (RJ) & 0.0230 \\
$10^{\circ}$ & Amapá (AP) & 0.1740 & $23^{\circ}$ & Roraima (RR) & 0.0197 \\
$11^{\circ}$ & Mato Grosso do Sul (MS) & 0.1606 & $24^{\circ}$ & Minas Gerais (MG) & 0.0121 \\
$12^{\circ}$ & Sergipe (SE) & 0.1350 & $25^{\circ}$ & Rondônia (RO) & 0.0111 \\
$13^{\circ}$ & Piauí (PI) & 0.1289 & $26^{\circ}$ & Rio Grande do Sul (RS) & 0.0077 \\
& & $27^{\circ}$ & Alagoas (AL) & 0 \\
\hline
\end{tabular}

Legenda: $\mathrm{P}$ = posição no ranking de desempenho; IDST = Índice de Desempenho da Subfunção Turismo dos Estados e do Distrito Federal.

Fonte: dados da pesquisa. 
O Índice de Desempenho da Subfunção Turismo dos Estados e do Distrito Federal (IDST) indica como foram aplicados os recursos pelas entidades de forma comparativa e náo representa um conjunto de dados isolados (foram utilizados recursos aplicados pelas entidades em cinco exercícios financeiros). A criação do ranking de desempenho é uma consequência para verificar as aplicaçôes de recursos (análise/avaliação comparativa).

Ao delimitar as variáveis que compóem o índice de desempenho, outras podem ficar de fora da avaliação, mas tal procedimento é natural, haja vista que avaliar todas as variáveis que expressam qualidade dos gastos públicos em artigos científicos não é possível pela quantidade de páginas que podem ser expressas. Convém ressalvar ainda, que em teses e dissertaçôes também existem delimitaçôes.

Observa-se na Tabela 3 que o Estado do Ceará (CE) obteve a primeira posição no ranking de desempenho na execução orçamentária da despesa da subfunçáo turismo (recursos públicos investidos).

O estado do Ceará (CE) foi destaque também nas pesquisas de Aragão e Dantas (2006), ao concluírem que o governo estadual utiliza o turismo para reforçar a imagem do estado como estável, avançado e moderno. E, Dantas (2007), ao avaliar os valores investidos pelos governos locais em parceria com organismos regionais e nacionais na Regiáo Nordeste, verificou que o Estado do Ceará (CE) ficou na segunda posição (53,428 milhōes de dólares).

O Estado de Pernambuco (PE), nesta investigação, ficou na segunda posição do ranking de investimentos públicos no período avaliado. Na pesquisa de Dantas (2007), ficou na última posição em relação aos recursos alocados pelos governos locais em parceria com organismos regionais e nacionais na Regiáo Nordeste.

O desempenho demonstrado na Tabela 3, leva em conta os valores aplicados na subfunção turismo per capita (valores individuais) normalizados pelos coeficientes (autovetores), média e o desvio-padrão do grupo (escores padronizados). Assim, no ranking geral, a maioria dos Estados (18) aplicou recursos abaixo da percentagem média geral (Amapá até Alagoas).

Pelo modelo principal-agente da Teoria da Agência, conforme esclarecimentos de Secchi (2013), pode-se esclarecer que na execução orçamentária da despesa da subfunção turismo, os cidadãos são os principais e os gestores públicos estaduais são os agentes. Assim, com base na argumentação dessa teoria (caso prático de aplicação no setor público), os resultados servem para diminuir a assimetria informacional existente entre os gestores públicos estaduais (agentes) que conhecem a gestão pública e os cidadãos (principais) que a desconhece.

Pela Teoria dos Stakeholders (SILVEIRA; YOSHINAGA; BORBA, 2005; VIEIRA, COSTA; BOAVENTURA, 2011; HARRISON; FREEMAN; ABREU, 2015), como partes interessadas, nesta investigação, estão os cidadãos (comunidade), os agentes de turismo e os gestores públicos estaduais e o distrital. Os cidadãos contribuem com recursos financeiros para a gestão pública, os agentes de turismo prestam informaçóes sobre viagens, roteiros turísticos, excursôes turísticas e demais esclarecimentos pertinentes e os gestores públicos gerenciam os recursos públicos. Observa-se assim, a aplicaçấo da Teoria dos Stakeholders na gestão pública. 
Na pesquisa de Vieira, Costa e Boaventura (2011) realizada na área do turismo (abordagem mais específica dos envolvidos na indústria do turismo), foram identificados como principais stakeholders: Ministério do Turismo, Serviço Brasileiro de Apoio às Micro e Pequenas Empresas (SEBRAE), Governo do Paraná, Federação do Comércio de Bens, Serviços e Turismo do Paraná (FECOMÉRCIO), Agência Brasileira de Viagens (ABAV), Associaçáo Brasileira da Indústria de Hotéis (ABIH), Empresa Brasileira de Turismo (EMBRATUR) e Dirigentes Municipais de Turismo.

A estratégia da pesquisa de avaliação de resultados serve para diminuir a assimetria da informação existente entre os gestores públicos e os cidadãos (ARAÚJO; SANCHEZ, 2005). Desse modo, observa-se que que os resultados apresentados na Tabela 3 esclarecem de forma comparativa, o desempenho na aplicação dos recursos da subfunção turismo. Os eleitores devem conhecer a oferta de serviços públicos (ROSENBLATT; SHIDLO, 1996). Neste caso, a subfunção turismo tem um papel relevante no desenvolvimento das regióes brasileiras e por consequência os cidadáos têm o direito de conhecerem as aplicaçôes de recursos e fazerem as comparaçóes.

Considerando que o IDST foi elaborado, nesta investigação, como contribuição para a literatura sobre avaliação de resultados de gestóes públicas, deixam de ser feitas comparaçóes com estudos anteriores, haja vista que não foram encontradas. As comparaçóes realizadas são de forma individual (DANTAS, 2007; ARAGÃO; DANTAS, 2006) e as demais citaçōes servem de subsídio para demonstrar a relevância do tema abordado.

$\mathrm{Na}$ última posiçáo no ranking de desempenho (Tabela 3) está o Estado de Alagoas (AL). Foi o Estado que menos aplicou recursos na subfunçáo turismo. Na pesquisa de Dantas (2007), ficou na quinta posição em relação aos valores investidos pelos governos locais em parceria com organismos regionais e nacionais na Região Nordeste. Silva (2014), esclarece que o Estado de Alagoas carece de planejamento estratégico que seja capaz de consolidar potenciais produtos turísticos, que possam ser integrados aos já existentes, ampliando a oferta de destinos, proporcionando aos turistas maiores opçóes, de acordo com os segmentos de turismo ofertados.

Chama atenção a vigésima segunda posição no ranking para o Estado do Rio Janeiro (RJ) na avaliaçáo comparativa com os demais estados e o Distrito Federal. Nos anos de 2013 e 2015 diminuiu a aplicação de recursos em relação aos demais anos avaliados (mais da metade). Lima (2014), diante de dilemas na área do turismo fluminense, apresenta contribuiçóes para melhorias na gestão pública. Assim, os achados de Lima (2014) ajudam compreender a situação dos resultados desta investigação em relação a esse estado.

As implicaçôes das avaliaçôes apontadas pelo Índice de Desempenho da Subfunção Turismo dos Estados e do Distrito Federal (IDST), embora utilize apenas os dados da execução orçamentária da despesa da subfunçáo turismo de 2011 a 2015, evidenciaram que Estados considerados com atrativos turísticos (por exemplos: São Paulo - 7o, Rio de Janeiro $-22^{\circ}$ etc.) não receberam na avaliaçáo comparativa recursos públicos de seus governantes para que assim sejam destacados (subfunção turismo).

Considerando que além de calcular o desempenho dos Estados e do Distrito Federal na alocação de recursos na subfunção turismo, esta investigação mostra os diversos passos 
para utilizar a técnica da Análise de Componentes Principais (ACP) para elaborar índices. Desse modo, a Tabela 4 apresenta o cálculo do escore de desempenho do componente 1 do Estado do Ceará (CE) - $1^{\circ}$ colocado no ranking de desempenho da execução orçamentária da subfunção turismo, no período de 2011 a 2015.

Tabela 4 - Cálculo do escore de desempenho do Estado do Ceará (CE)

$Y_{1}=0.4040(4.33976)+0.4518(3.57850)+0.4603(1.57992)+0.4558(1.76150)+0.4614$ $(1.80612)=5.7340$

$\mathrm{Y}_{1}=$ escore de desempenho do componente 1 .

Resultado final $=5.7340$ (maior escore $=1$ na interpolação).

Fonte: dados da pesquisa.

Observa-se na Tabela 4, que o escore de desempenho do Estado do Ceará (CE) foi de 5.7340, o qual foi considerado 1 na interpolação. Assim, os escores finais de desempenho ficaram na faixa de 1 (maior eficiência alocativa) a 0 (menor eficiência). Os escores de desempenho calculados com a técnica da Análise de Componentes Principais (ACP) apresenta valores positivos e negativos.

Os resultados obtidos e análises permitiram a elaboração de um índice de desempenho de forma a ranquear a posição dos Estados Brasileiros e do Distrito Federal em relação ao orçamento público da subfunção turismo. Isso permite inferir sobre a eficiência da gestão na alocação de recursos públicos. A discussão e comparação entre entes públicos podem e devem ser ampliadas, principalmente, pois analisar o desempenho das políticas públicas é somente uma forma, sendo bem mais amplo o campo de análise.

\section{CONSIDERAÇÓES FINAIS}

As funçóes de governo representam uma visão macro em que os recursos públicos foram aplicados para atender a sociedade nos diversos serviços. As entidades públicas devem avaliar os seus programas para certificarem que os resultados sejam atingidos. A análise de desempenho, além de cumprir com essa finalidade, pode ser efetuada para melhorar o seu desempenho.

Neste sentido, esta investigação elaborou um índice de desempenho dos Estados Brasileiros e do Distrito Federal na execução orçamentária da despesa da subfunção turismo, no período de 2011 a 2015. O Índice de Desempenho da Subfunção Turismo dos Estados e do Distrito Federal (IDST) indica como foram aplicados os recursos pelas entidades (Estados Brasileiros e o Distrito Federal) de forma comparativa, a partir da utilização da métrica Análise de Componentes Principais (ACP) que padroniza as variáveis e utiliza os escores dos componentes principais em equações lineares.

O Índice de Desempenho da Subfunção Turismo dos Estados e do Distrito Federal (IDST) avalia a eficiência alocativa dos gestores públicos ao administrarem os recursos da execução orçamentária das despesas da subfunção turismo. 
Como limitação do estudo, pode-se destacar o fato da abordagem ser restritiva a utilização de recursos financeiros (execução orçamentária da despesa da subfunção turismo) em uma área (turismo) que envolve muitos stakeholders, além de ser utilizado apenas recursos dos governos estaduais e distrital. Contudo, avaliar todo o universo de variáveis que compóem a área do turismo não é possível. Deve-se delimitar a área de avaliação/análise para assim poder realizar as contribuiçóes. Recomenda-se a realização de mais pesquisas avaliativas no setor público, haja vista que os dados devem ser obrigatoriamente divulgados nos portais de transparência. Neste sentido, podem ser realizadas pesquisas sobre os gastos da subfunção turismo com os municípios.

A pesquisa contribui no esclarecimento e auxílio para a sociedade em encontrar suporte e orientações para o controle social. Para a literatura, a contribuição principal se refere a questôes relacionados com a elaboração de índices com métrica quantitativa e avaliaçáo das políticas públicas do turismo que têm um impacto no desenvolvimento do país. Os indicadores sociais têm um papel essencial para a implementação e avaliação de desempenho das políticas públicas.

A Teoria dos Stakeholders e a Teoria da Agência foram utilizadas como suportes para o entendimento dos achados da pesquisa em relação a identificação e o papel dos principais interessados na gestáo e a assimetria informacional existente entre o gestor público e os cidadãos, respectivamente. Observa-se assim, que são casos de aplicação das teorias.

Foram identificados como principais stakeholders (partes interessadas) na execução orçamentária da despesa da subfunção turismo: os cidadáos (comunidade), os agentes de turismo e os gestores públicos estaduais e o distrital. Os cidadáos têm o direito de conhecerem como os recursos disponibilizados foram aplicados (controle social). Os agentes de turismo estão interessados na infraestrutura e apoio que o Estado proporciona no sentido de fortalecer o desenvolvimento do turismo. Os gestores públicos estaduais e o distrital têm a obrigação de aplicarem os recursos com eficiência (exigência constitucional).

Finalizando e respondendo ao problema de pesquisa, os resultados apontaram no ranking de desempenho dos Estados e do Distrito Federal na execuçáo orçamentária da subfunção turismo, no período de 2011 a 2015, com a elaboração do Índice de Desempenho da Subfunção Turismo dos Estados e do Distrito Federal (IDST), que o estado do Ceará (CE), seguido de Pernambuco (PE) e Santa Catarina (SC) obtiveram as primeiras posiçóes (mais eficientes). Nas últimas posiçôes ficaram os Estados de Rondônia - RO com a 25a posição, Rio Grande do Sul - RS, na 26a e na última posição (27a), Alagoas - AL (menos eficiente).

Os achados trazem como implicações que Estados considerados com atrativos turísticos (por exemplos: São Paulo $-7^{\circ}$, Rio de Janeiro $-22^{\circ}$ etc.) não receberam na avaliação comparativa recursos públicos de seus governantes para que assim sejam destacados (subfunçáo turismo). Isto sugere que a iniciativa privada tem exercido um papel relevante na área do turismo e o setor público não. 


\section{REFERÊNCIAS}

ALMEIDA, G. S. Desenvolvimento sustentável para pequenos municípios através do turismo rural: uma metodologia de avaliação do potencial de serviços turísticos. 204 f. Dissertação (Mestrado em Engenharia da Produção). Universidade Federal de Santa Catarina - UFSC. Programa Pós-Graduação em Engenharia de Produção, 2003.

ARAGÃO, R. F.; DANTAS, E. W. C. Elaboração da imagem turística do Ceará: entre publicidade turística e propaganda política. Geosul, Florianópolis, v. 21, n. 42, p 45-62, jul./dez, 2006.

ARÁUJO, M.; SANCHEZ, O. A. A corrupção e os controles internos do Estado. Lua Nova, São Paulo, 65: p.137-173, 2005.

ARAÚJO, R. M.; POSENATTO, A. F. G. Plano de Fortalecimento da Gestão do Turismo (PFGT): uma avaliação ex ante no município de Nísia Floresta (RN). RAP Revista de Administração Pública, Rio de Janeiro, 46(1):221-48, jan./fev., 2012.

ARIAS, E. R. Estadística: Medición, Descripción e Inferencia. Perspectivas Psicológicas, Santo Domingo (Rep. Dom.), Volúmenes 6 y 7, año X. ISSN 1992-5131, Edición Especial, 2010.

ARROW, K. J. The Economics of Agency. Institute for Mathematical Studies in The Social Sciences, Stanford University, California, octuber 1984.

AYRES, M. Elementos de bioestatística: a seiva do açaizeiro. 2. ed. Belém: Supercores, 2012.

AYRES, M.; AYRES JÚNIOR, M.; AYRES, D. L.; SANTOS, A. A. S.; AYRES, L. L. BioEstat 5.0 - Aplicações estatísticas nas áreas das ciências biomédicas. Belém, PA: Sociedade Civil Mamirauá, PA, 2007.

BARBOSA, L. G.; MARTELOTTE, M. C.; ZOUAIN, D. M. Os impactos econômicos do turismo no município do Rio de Janeiro e suas implicaçóes no desenvolvimento local. Turismo - Visáo e Ação, vol. 8 - n.3 p. 397-409, set./dez., 2006.

BASTOS, C. R. Avaliação dos impactos socioeconômicos do turismo na regiáo metropolitana de Fortaleza (Ceará-Brasil). Tese (Doutorado em "Planificación y Desarrollo Regional”). Universidad de Barcelona. Facultad de Geografía e Historia. 2012.

BASTOS, C. L.; KELLER, V. Aprendendo a aprender: introdução à metodologia científica. 17. ed. Petrópolis: Vozes, 2004.

BOAVENTURA, J. M. G. (2012). Dominância de stakeholders em empresas brasileiras: contribuiçóes à teoria dos stakeholders. Tese (Livre-Docente).

Departamento de Administraçáo da Faculdade de Economia da Universidade de São Paulo, São Paulo, SP., 2012. 
BRASIL. Lei no 4.320, de 17 de março de 1964. Estatui normas gerais de direito financeiro para elaboração e controle dos orçamentos e balanços da União, Estados, Municípios e do Distrito Federal. Diário Oficial [da] República Federativa do Brasil, Brasília, DF, 23 de março de 1964.

. Ministério do Planejamento, Orçamento e Gestão (MPOG). Portaria no 42, de 14 de abril de 1999. Atualiza a discriminação da despesa por funções de que tratam o inciso I do $\$ 1^{\circ}$ do art. $2^{\circ}$ e $\$ 2^{\circ}$ do art. $8^{\circ}$, ambos da Lei $n^{\circ} 4.320$, de 17 de março de 1964 , estabelece os conceitos de função, subfunção, programa, projeto, atividade, operaçóes especiais, e dá outras providências. Diário Oficial [da] República Federativa do Brasil, Brasília-DF, 15 de abril de 1999.

. Ministério do Planejamento, Orçamento e Gestão (MPOG). Secretaria de Gestão. Melhoria da gestão pública por meio da definição de um guia referencial para medição do desempenho da gestão, e controle para o gerenciamento dos indicadores de eficiência, eficácia e de resultados do programa nacional de gestão pública e desburocratização. Produto 4: guia referencial para medição de desempenho e manual para construção de indicadores. Brasília-DF, dezembro, 2009.

. Tribunal de Contas da União. Portaria SEGECEX no 33, de 23 de dezembro Técnica de indicadores de desempenho para auditorias. Brasília, 11 de janeiro de 2011 - Ano XLIV - No 3, 2010.

. Tribunal de Contas da União. Técnicas de Auditoria: indicadores de desempenho e mapa de produtos. Boletim do Tribunal de Contas da União. Brasília-DF: TCU, Coordenadoria de Fiscalização e Controle, 32p., 2000.

. Ministério da Fazenda. Secretaria do Tesouro Nacional (STN). Sobre Prefeituras e Governos Estaduais. Disponível em: < https:/www.tesouro.fazenda.gov.br/finbrafinancas-municipais>. Acesso em: 10 fev. 2017.

BROWN, K. W. The 10-Point Test of Financial Condition: Toward an Easy-to-Use Assessment Tool for Smaller Cities. Government Finance Review, p. 21-26, December, 1993.

BUGARIN, P. S. O princípio constitucional da eficiência: um enfoque doutrinário multidisciplinar. R. TCU, Brasília, v. 32, n. 87, p. 39-50, jan/mar., 2001.

CABRAL, S., FERNANDES, A. S. A.; RIBEIRO, D. B. C. Os Papéis dos Stakeholders na Implementação das Parcerias Público-Privadas no Estado da Bahia. Cad. EBAPE.BR, v. 14, no 2, Artigo 6, Rio de Janeiro, Abr./Jun., 2016.

CAIDEN; G. E.; CAIDEN, N. J. Enfoques y lineamientos para el seguimiento, la medición y la evaluación del desempeño en programas del sector público. Revista do Serviço Público. Ano 52, Número 1, pp. 78-102, Jan-Mar., 2001. 
CATALÁN, P. H.; BALLVE, P. F. Análisis de la eficiencia del gasto municipal y de sus determinantes. Economía, Vol. XXXII, nº 63, pp. 113-178, semestre enero-junio, 2009.

COHEN, E.; FRANCO, R. Avaliaçáo de projetos sociais. 10. ed. Petrópolis: Vozes, 2012.

CONNOLLY, C.; HYNDMAN, N. Towards charity accountability: narrowing the gap between provision and needs? Public Management Review, 15:7, 945-968., 2013.

CORRÊA, C. C.; MARIANI, M.; VELOSO, A. Avaliação da cadeia produtiva do turismo no estado de Mato Grosso do Sul: regiáo dos Lagos. GEPROS. Gestáo da Produçáo, Operaçóes e Sistemas, Ano 6, no 2, Abr-Jun, p. 33-55., 2011.

COSTA, B. K.; AMÂNCIO-VIEIRA, S. F.; ALEXANDRE, M. L. O.; CARMONA, V. C. Articulação de stakeholders e estratégias no setor turístico brasileiro: uma investigação em localidades. R. Adm. FACES Journal, Belo Horizonte v. 15 n. 3 p. 8-26 jul./set., 2016.

COSTA, F. L.; CASTANHAR, J. C. Avaliação de programas públicos: desafios conceituais e metodológicos. RAP - Revista de Administração Pública, Rio de Janeiro 37 (5): 96992, Set./Out., 2003.

DANTAS, W. W. C. Imaginário social nordestino e políticas de desenvolvimento do turismo no nordeste brasileiro. GEOUSP - Espaço e Tempo, São Paulo, no 22, pp. 09 30, 2007.

DINIZ, J. A.; MACEDO, M. A. S.; CORRAR, L. J. Mensuração da eficiência financeira municipal no Brasil e sua relação com os gastos nas funções de governo. Gestáo \& Regionalidade, vol. 28 - no 83 - mai-ago., 2012.

DRAIBE, S. M. Avaliação de implementação: esboço de uma metodologia de trabalho em políticas públicas. In: BARREIRA, M. C. R. N.; CARVALHO; M. C. B. (Org.). Tendências e perspectivas na avaliaçáo de políticas e programas sociais. São Paulo: IEE/PUC-SP, 2001.

DONALDSON, T.; PRESTON, L. The stakeholders theory of the corporation: concepts, evidence and implications. Academy of Management Review, v. 20, n.1, 65-91, 1995.

FIELD, A. Descobrindo a estatística usando o SPSS. Traduçáo de Lorí Viali. 2. ed. Porto Alegre: Artmed, 2009.

FIGUEIREDO FILHO, D. B.; PARANHOS, R.; ROCHA, E. C.; SILVA JÚNIOR, J. A.; MAIA, R. G. Análise de componentes principais para construção de indicadores sociais. Rev. Bras. Biom. v. 31, n. 1, p. 61-78, 2013. 
FRANCO-SANTOS, M.; LUCIANETTI, L.; BOURNE, M. Contemporary

Performance Measurement Systems: a review of their consequences and a framework for research. Management Accounting Research, v. 23, n. 2, p. 79-119, 2012.

FREEMAN, R. E.; HARRISON, J. S.; WICKS, A. C.; PARMAR, B.; COLLE, S. Stakeholder Theory: The State of the Art. Cambridge University Press, Cambridge, 2010.

GIRALDES, M. R. Avaliação do SNS em Portugal: equidade versus eficiência. Economia da Saúde, Vol. 23, No 2, p. 21-44, julho/dezembro, 2005.

GOMES, R. C. Stakeholder Management in the Local Government Decision-Making Area: Evidences from a Triangulation Study with the English Local Government. RAC Revista de Administração Contemporânea, Edição Especial: 77-98, 2006.

HARRISON, J. A.; ROUSE, P.; DE VILLIERS, C. J. Accountability and Performance Measurement: A Stakeholder Perspective. JCC: The Business and Economics Research Journal, Volume 5, Issue 2, 243-258, 2012.

HARRISON, J. S.; FREEMAN, R. E.; ABREU, M. C. S. Stakeholder Theory as an Ethical Approach to Effective Management: applying the theory to multiple contexts. Review of Business Management, São Paulo, Vol. 17, No. 55, pp. 858-869, Special Edition, 2015.

HELDEN, G. J. V.; JOHNSEN, A.; VAKKURI, J. Distinctive research patterns on public sector performance measurement of public administration and accounting disciplines. Public Management Review, 10:5,641-65, 2008.

JANNUZZI, P. M. Consideraçóes sobre o uso, mau uso e abuso dos indicadores sociais na formulação e avaliação de políticas públicas municipais. RAP - Revista de Administração Pública, Rio de Janeiro 36 (1): 51-72, Jan./Fev, 2002.

JENSEN, M. C.; MECKLING, W. H. Theory of the firm: managerial behavior, agency costs and ownership structure. Journal of Financial Economics, October, V. 3, No. 4, pp. 305-360, 1976.

JOHNSON, R. A.; WICHERN, D. W. Applied Multivariate Statistical Analysis. 6. ed. New Jersey: Prentice Hall, 2007.

JOLLIFFE, I. T. Principal component analysis. 2nd. edition. New York: SpringerVerlag, 2002.

KAISER, H. F. The application of electronic computers to factor analysis. Educational and Psychological Measurement, v. 20, p. 141-151, 1960. 
KUBRUSLY, L. S. Um procedimento para calcular índices a partir de uma base de dados multivariados. Pesquisa Operacional, vol. 21, no. 1, p. 107-117, junho, 2001.

LARSON, R.; FARBER, B. Estatística aplicada. Tradução de Luciane Ferreira Paulete Vianna. 4. ed. São Paulo: Pearson Prentice Hall, 2010.

\section{LATTIN, J.; CARROLL, J. D.; GREEN, P. E. Análise de dados multivariados.}

Tradução de Harue Avritscher. São Paulo: Cengage Learning, 2011.

LERUTH, L., Paul, E. A principal-agent theory approach to public expenditure management systems in developing countries. IMF Working Paper, 06/204, September, p. $1-43,2006$.

LIMA, V. M. S. Gestão pública do turismo no estado do Rio de Janeiro: dilemas e perspectivas. Revista Eletrônica Sistemas \& Gestáo, Volume 9, Número 3, pp. 356-36, 2014.

LINS, M. P. E.; CALÔBA, G. M. Programação linear: com aplicações em teoria dos jogos e avaliação de desempenho. Rio de Janeiro: Interciência, 2006.

MAHER, C. S.; NOLLENBERGER, K. Revisiting Kenneth Brown's “10-Point Test”. Government Finance Review, October, 2009.

MANLY, B. J. F. Métodos estatísticos multivariados: uma introdução. Tradução de Sara Ianda Carmona. 3. ed. Porto Alegre: Bookman, 2008.

MARÔCCO, A. P. A avaliação de implementação de política de ciência, tecnologia e inovação à luz da teoria da agência. Jornal Eletrônico, Ano 1 - Edição I - julho, p. 1-37, Faculdades Integradas Vianna Júnior, 2009.

MARTINS, G. A. Estatística geral e aplicada. 2. ed. São Paulo: Atlas, 2002.

MARTINS, G. A. Falando sobre teorias e modelos nas ciências contábeis. BBR Brazilian Business Review, Vol. 2, no 2, Vitória-ES, Brasil - Jul / Dez 2005, pp. 131$144,2005$.

MARTINS, G. A.; THEÓPHILO, C. R. Metodologia da investigaçáo científica para ciências sociais aplicadas. 2. ed. São Paulo: Atlas, 2009.

MATIAS-PEREIRA, J. Manual de metodologia da pesquisa Científica. 3. ed. São Paulo: Atlas, 2012.

MATIAS-PEREIRA, J. Reforma do estado e controle da corrupção no Brasil. Caderno de Pesquisas em Administraçáo, São Paulo, v. 12, n. 2, p.1-17, abril/junho, 2005.

MCWILLIAMS, A.; SIEGEL, D. Corporate social responsibility: a theory of the firm perspective. The Academy of Management Review, 26(1), 117-127, 2001. 
MEIRELLES, N. R. Turismo: diagnóstico pernambucano e os dispêndios públicos realizados no período de 1997 a 2007. Dissertação (Mestrado em Economia). Universidade Federal de Pernambuco (UFPE), Departamento de Economia, 2009.

MINGOTI, S. A. Análise de dados através de métodos de estatística multivariada: uma abordagem aplicada. 1a reimpressão. Belo Horizonte: Editora UFMG, 2007.

MINGOTI, S. A.; SILVA, A. F. Um exemplo de aplicação de técnicas de estatística multivariada na construção de índices de preços. Nova Economia, Belo Horizonte, v. 7, n. 2, 1997.

MITCHELL, R. K.; AGLE, B.R.; WOOD, D.J. Toward a theory of stakeholder identification and salience: defining the principle of who and what really counts. Academy of Management Review, v. 22, n. 4, 853-886, 1997.

NINA, D. A.; FERNÁNDEZ, G. M. Q. Medición de la eficiencia asignativa mediante el análisis envolvente de datos en los municipios de Bolivia: caso municipios de Potosí. Departamento de Administración, Economía y Finanzas, Revista Perspectivas, año 14, $\mathrm{n}^{\circ}$ 28, pp. 137-139, 2 do Semestre, 2011.

OSBORNE, J. W.; COSTELLO, A. B. Sample size and subject to item ratio in principal components analysis. Practical Assessment, Research \& Evaluation, 9 (11), 2004.

PINTO, D. W.; KOZIKOWSKI, H. P.; PILLATI, J. J.; CHELSKI, W.; SAMAHA, M. J. Teoria da Agência e o controle social da gestão pública. Revista Organizaçáo Sistêmica, vol.5, n. 3, jan/jun, p.100-109, 2014.

RAMOS, M. P.; SCHABBACH, L. M. O estado da arte da avaliação de políticas públicas: conceituação e exemplos de avaliação no Brasil. Rev. Adm. Pública - Rio de Janeiro 46(5):1271-294, set./out, 2012.

REZENDE, F. C. Descentralização, gastos públicos e preferências alocativas dos governos locais no Brasil (1980-1994). Dados, v. 40, n. 3, Rio de Janeiro, 1997.

RIBAS, J. R.; VIEIRA, P. R. C. Análise multivariada com o uso do SPSS. Rio de Janeiro: Ciência Moderna, 2011.

ROSENBLATT, D.; SHIDLO, G. Quem tem mais recursos para governar? Uma comparação das receitas per capita dos estados e dos municípios brasileiros. Revista de Economia Aplicada, vol. 16, no 1 (61), p. 101-106, janeiro-março, 1996.

SARTURI, G.; SERAVALLI. C.; BOAVENTURA, J. M. G. Afinal, o que é distribuir valor para os stakeholders? Uma análise bibliográfica sobre o tema. Revista de

Administração da UFSM, v. 8, n. ed. especial, p. 92-113, 2015. 
SECCHI, L. Políticas públicas: conceitos, esquemas de análise, casos práticos. 2. Ed. São Paulo: Cengage Learning, 2013.

SILVA, B. P. Infraestrutura logística e o turismo em Alagoas no período de 20042013. 112 f. Dissertação (Mestrado em Economia Aplicada). Universidade Federal de Alagoas. Faculdade de Economia, Administração e Contabilidade, Maceió, 2014.

\section{SILVA, M. C. Avaliação de desempenho de governos municipais brasileiros na} execução orçamentária da despesa por funçóes de governo. Tese (Doutorado em Ciências Contábeis). Programa Multi-institucional e Inter-regional de Pós-Graduação em Ciências Contábeis da Universidade de Brasília (UnB), Universidade Federal da Paraíba (UFPB) e Universidade Federal do Rio Grande do Norte (UFRN). Natal, RN, 2016.

SILVA, M. C.; SILVA, R. A.; SILVA, J. D. G. Análise e avaliação de políticas públicas: aspectos conceituais. Boletim de Administraçáo Pública e Gestáo Municipal, n. 61, outubro, p. 1434 - 1444, 2016.

SILVA, M. C.; SILVA, J. D. G. Avaliação de desempenho de governos municipais brasileiros na execução orçamentária da despesa por funçóes de governo. Revista Perspectivas Contemporâneas, v. 12, n. 1, p. 214-236, jan./abr, 2017.

SILVEIRA, A. D. M.; YOSHINAGA, C. E.; BORBA, P. R. F. Crítica à teoria dos stakeholders como função-objetivo corporativa. Caderno de Pesquisas em Administração, São Paulo, v. 12, n. 1, p. 33-42, janeiro/março, 2005.

STEVENSON, W. J. Estatística aplicada à administração. São Paulo: Harper \& Row do Brasil, 1981,

SUZART, J. A. S. As Instituições Superiores de Auditoria: um estudo do nível de transparência fiscal dos países. Contabilidade, Gestáo e Governança - Brasília, v. 15, n. 3, p. 107-118, set./dez, 2012.

TIMM, N. H. Applied multivariate analysis. New York: Springer-Verlag, 2002.

VIEIRA, S. F. A.; COSTA, B. K.; BOAVENTURA, J. M. G. Análise de stakeholders aplicada em órgáos públicos: o caso da Secretaria de Estado do Turismo do Paraná.

Revista de Ciências da Administração, v. 13, n. 31, p. 81 - 110, set/dez, 2011.

VYAS, S.; KUMARANAYAKE, L. Constructing socio-economic status indices: how to use principal components analysis. Health Policy and Planning, 9 October. 21 (6):459468, 2006.

ZUCATTO, L. C.; SARTOR, U. M.; BEBER, S.; WEBER, R. Proposição de indicadores de desempenho na gestão pública. ConTexto, Porto Alegre, v. 9, n. 16, $2^{\circ}$ semestre, 2009. 